\title{
Hole mobilities of thermally polymerized triaryldiamine derivatives and their application as hole-transport materials in organic light-emitting diodes (OLEDs)
}

\author{
Chi-Yen Lin ${ }^{a}$, You-Ming Chen ${ }^{a}$, Hsiao-Fan Chen ${ }^{a}$, Fu-Chuan Fang ${ }^{a}$, Yu-Cheng Lin ${ }^{b}$, \\ Wen-Yi Hung $^{b, *}$, Ken-Tsung Wong ${ }^{a, *}$, Raymond C. Kwong ${ }^{c}$, Sean C. Xia ${ }^{c}$ \\ ${ }^{a}$ Department of Chemistry, National Taiwan University, Taipei 106, Taiwan, ROC \\ ${ }^{\mathrm{b}}$ Institute of Optoelectronic Sciences, National Taiwan Ocean University, Keelung 202, Taiwan, ROC \\ ' Universal Display Corporation, 375 Phillips Blvd, Ewing, NJ 08618, USA
}

\section{A R T I C L E I N F O}

\section{Article history:}

Received 21 August 2008

Received in revised form 5 November 2008

Accepted 7 November 2008

Available online 18 November 2008

PACS:

73.50.-h

73.61.Ph

78.30.Jw

78.55.Kz

78.60.Fi

78.66.Qn

Keywords:

Solution process

Thermal polymerization

Time-of-flight (TOF)

Hole mobility

\begin{abstract}
A B S T R A C T
This paper describes the synthesis of three triaryldiamine derivatives presenting two thermally polymerizable trifluorovinyl ether groups that can be polymerized through thermal curing to form perfluorocyclobutyl (PFCB) polymers. These PFCB polymers, studied using time-of-flight techniques for the first time, exhibited remarkable non-dispersive holetransport properties, with values of $\mu_{\mathrm{h}}$ of ca. $10^{-4} \mathrm{~cm}^{2} \mathrm{~V}^{-1} \mathrm{~s}^{-1}$. When we employed these thermally polymerized polymers as hole-transport layers (HTLs) in electroluminescence devices containing tris(8-hydroxyquinolate) aluminum $\left(\mathrm{Alq}_{3}\right)$ as the emission layer, we obtained high current densities (ca. $3400 \mathrm{~mA} \mathrm{~cm}^{-2}$ ), impressive brightnesses $(5 \times$ $10^{4} \mathrm{~cd} \mathrm{~m}^{-2}$ ), and high external quantum efficiencies (EQEs $=1.43 \%$ ). These devices exhibited the same turn-on voltage, but higher EQEs, relative to those incorporating the vacuum-processed model compound $N, N^{\prime}$-di(1-naphthyl)- $N, N^{\prime}$-diphenylbenzidine ( $\alpha$-NPD) $(\mathrm{EQE}=1.37 \%)$ as the HTL under the same device structure.
\end{abstract}

(c) 2008 Elsevier B.V. All rights reserved.

\section{Introduction}

Organic and polymer light-emitting diodes are promising devices for use in future lighting and display applications because of their low power consumption, light weight, fast response, and wide viewing angle [1,2]. To increase their efficiency, most organic light-emitting diodes (OLEDs) are configured with a variety of functional materials into a multilayer structure-fabricated through succes-

\footnotetext{
* Corresponding authors. Tel.: +886 2 33661665; fax: +886 233661667.

E-mail addresses: wenhung@mail.ntou.edu.tw (W.-Y. Hung), kenwong @ntu.edu.tw (K.-T. Wong).
}

sive vacuum deposition of small molecules-and then covered by a metal cathode. It is generally inherently difficult to form polymer-based OLEDs in multilayer structures through solution-processing techniques, such as spin-coating, because of solvent erosion of the previously deposited layers during spin-coating [3]. One of the most promising approaches toward achieving purely solution-processed multiple-layer polymer-based OLEDs is utilizing soluble precursor materials to produce insoluble polymer networks through polymerization and/or cross-linking reactions. This strategy allows the sequential deposition of various functional layers [4,5]. The flexibility of using the chemical modifications of a wide variety of materials 
possessing various functional moieties-such as siloxan [69], norbornene [10,11], oxetane [4,5], vinyl [12,13], and trifluorovinyl ether [14-18] units-as polymerizable groups under UV irradiation or thermal curing allows the construction of copolymers in nearly any designated composition. For example, trifluorovinyl ether (TFVE)-containing compounds are useful as reactive monomers that undergo thermal cyclopolymerization to afford a new class of thermally stable perfluorocyclobutane (PFCB) polymers [19-21]. Taking advantage of this strategy, PFCB-based hole-transport materials have been developed to increase the efficiency of OLED devices [22-28]. This superior performance is ascribed mainly to the homogeneous surface morphology of the thermally treated thin films, as probed using atomic force microscopy (AFM). Nevertheless, to the best of our knowledge, the intrinsic charge transporting characteristic, one of the most critical factors in optoelectronic devices, of PFCB-based hole-transport materials has not been reported previously. In this paper, we report the synthesis, characterization, and application of three triaryldiamine derivatives attached to two thermally polymerizable trifluorovinyl ether (TFVE) groups that can be polymerized through thermal curing to form PFCB polymers. More importantly, we have used time-of-flight (TOF) techniques to study the hole-transport properties of these polymers. We have found that PFCB-based polymers possess remarkable hole-transport properties, with values of $\mu_{\mathrm{h}}$ of ca. $10^{-4} \mathrm{~cm}^{2} \mathrm{~V}^{-1} \mathrm{~s}^{-1}$. These thermally polymerized polymers are useful as hole-transport layers (HTLs) in electroluminescence (EL) applications, as evidenced by the high external quantum efficiency of $1.43 \%$ achieved when employing one such system with tris(8-hydroxyquinolate) aluminum $\left(\mathrm{Alq}_{3}\right)$ as the emission layer.

\section{Experimental}

\subsection{Synthesis}

Compound 5: Compound 4 (5.08 g, $10 \mathrm{mmol}), \mathrm{N}$-phenyl-1-naphthylamine (4.39 g, $20 \mathrm{mmol}), \mathrm{Pd}(\mathrm{OAc})_{2}(67 \mathrm{mg}$, $0.3 \mathrm{mmol})$, and sodium tert-butoxide $(7.68 \mathrm{~g}, 80 \mathrm{mmol})$ were dissolved in toluene $(100 \mathrm{~mL})$ and then tri-tert-butylphospine ( $6 \mathrm{~mL}, 0.05 \mathrm{M}$ in toluene, $0.3 \mathrm{mmol}$ ) was added. The mixture was heated under reflux under argon for $72 \mathrm{~h}$ and then quenched with water. The solution was partitioned between ethyl acetate and brine. The combined organic extracts were dried $\left(\mathrm{MgSO}_{4}\right)$ and concentrated. The resulting solid was washed with hexane to afford a yellow product $(6.41 \mathrm{~g}, 82 \%)$. M.p. $254-255^{\circ} \mathrm{C}$. IR (KBr) $v$ 3544 (w), 3055 (w), 1609 (m), 1592 (s), 1573 (m), 1507 (s), $1489(\mathrm{~s}), 1464(\mathrm{~s}), 1434(\mathrm{~m}), 1392(\mathrm{~m}), 1302(\mathrm{~m})$, 1269 (s), $1172(\mathrm{~m}), 1015(\mathrm{~m}) \mathrm{cm}^{-1} .{ }^{1} \mathrm{H}$ NMR (DMSO-d $d_{6}$, $400 \mathrm{MHz}): \delta 9.29$ (s, 2H), $7.97(\mathrm{~d}, J=8.0 \mathrm{~Hz}, 2 \mathrm{H}), 7.84$ (d, $J=8.4 \mathrm{~Hz}, 2 \mathrm{H}), 7.76(\mathrm{~d}, J=8.4 \mathrm{~Hz}, 2 \mathrm{H}), 7.56-7.48(\mathrm{~m}, 6 \mathrm{H})$, $7.37(\mathrm{t}, J=7.4 \mathrm{~Hz}, 2 \mathrm{H}), 7.28(\mathrm{~d}, J=7.2 \mathrm{~Hz}, 2 \mathrm{H}), 7.16(\mathrm{t}$, $J=7.6 \mathrm{~Hz}, 4 \mathrm{H}), 6.92-6.84(\mathrm{~m}, 8 \mathrm{H}), 6.78(\mathrm{~s}, 2 \mathrm{H}), 6.51(\mathrm{~d}$, $J=8.8 \mathrm{~Hz}, 4 \mathrm{H}), 6.41$ (d, $J=8.4 \mathrm{~Hz}, 4 \mathrm{H}) .{ }^{13} \mathrm{C}$ NMR (DMSO$\left.d_{6}, 100 \mathrm{MHz}\right): \delta 155.5,152.2,147.5,146.5,142.6,135.3$, $134.7,132.9,130.1,129.1,128.4,128.2,126.6,126.4$, $126.3,126.1,123.4,121.6,121.1,120.4,120.2,118.8$,
114.6, 63.0. MS (FAB $\left.{ }^{+}, m / z\right) 785$ (100), 784 (65), 154 (70), 136 (65), 57 (65). HRMS (FAB $\left.{ }^{+},[\mathrm{M}+\mathrm{H}]^{+}\right)$Calcd. $\mathrm{C}_{57} \mathrm{H}_{41} \mathrm{~N}_{2} \mathrm{O}_{2}$ 785.3170, found 785.3165.

Compound 6: A mixture of $5(2.93 \mathrm{~g}, 3.73 \mathrm{mmol})$ and triethylamine ( $3 \mathrm{~mL}, 21.6 \mathrm{mmol}$ ) in dry dichloromethane $\left(260 \mathrm{~mL}\right.$ ) was cooled to $-10^{\circ} \mathrm{C}$. Trifluoromethanesulfonic anhydride $(1.9 \mathrm{~mL}, 11.2 \mathrm{mmol})$ in dry dichloromethane $(90 \mathrm{~mL})$ was added dropwise and then the reaction mixture was warmed to room temperature and stirred for $16 \mathrm{~h}$. The reaction was quenched by pouring the mixture into ice water. The organic layer was separated and the aqueous phase was extracted twice with dichloromethane. The combined organic extracts were washed with saturated $\mathrm{NaHCO}_{3}$ solution and brine and then dried $\left(\mathrm{MgSO}_{4}\right)$. The solvents were evaporated and the resulting residue was purified through re-precipitation from dichloromethane and methanol to afford a yellow product $(3.18 \mathrm{~g}$, $81 \%$ ). M.p. $136-138^{\circ} \mathrm{C}$. IR (KBr) v 3059 (w), 1609 (m), 1592 (m), $1573(\mathrm{~m}), 1494$ (s), 1468 (s), 1455 (m), 1426 (s), $1392(\mathrm{~m}), 1271(\mathrm{~m}), 1249(\mathrm{~m}), 1212(\mathrm{~s}), 1140(\mathrm{~s}), 884$ (m), $774(\mathrm{~m}) \mathrm{cm}^{-1} .{ }^{1} \mathrm{H}$ NMR (DMSO-d, $400 \mathrm{MHz}$ ): $\delta 7.96$ (d, J=8.4 Hz, 2H), 7.85 (d, J=8.0 Hz, 2H), 7.72 (d, $J=8.0 \mathrm{~Hz}, 2 \mathrm{H}), 7.62(\mathrm{~d}, J=8.4 \mathrm{~Hz}, 2 \mathrm{H}), 7.53-7.46(\mathrm{~m}, 4 \mathrm{H})$, $7.37-7.27(\mathrm{~m}, 8 \mathrm{H}), \quad 7.15(\mathrm{t}, J=7.6 \mathrm{~Hz}, 4 \mathrm{H}), 7.00$ (d, $J=8.4 \mathrm{~Hz}, 4 \mathrm{H}), 6.92-6.89(\mathrm{~m}, 4 \mathrm{H}), 6.84(\mathrm{~d}, J=8.4 \mathrm{~Hz}, 6 \mathrm{H})$. ${ }^{13} \mathrm{C}$ NMR (DMSO- $\left.d_{6}, 100 \mathrm{MHz}\right): \delta 149.9,147.7,147.2$, $146.9,145.0,142.3,134.7,132.8,129.9,129.3,129.0$, $128.4,126.7,126.5,126.4,126.3,126.0,123.2,121.8$, 121.3, 121.1, 120.8, 119.6, 118.3,116.4, 63.6. MS (FAB ${ }^{+}$, $m / z) 1048$ (100), 916 (15), 690 (20), 218 (40), 217 (35). HRMS (FAB ${ }^{+}, \mathrm{M}^{+}$) Calcd. $\mathrm{C}_{59} \mathrm{H}_{38} \mathrm{~F}_{6} \mathrm{~N}_{2} \mathrm{O}_{6} \mathrm{~S}_{2}$ 1048.2075, found 1048.2076.

TFVE1: 1 (380 mg, $0.87 \mathrm{mmol}$ ), 2 (515 mg, $2.18 \mathrm{mmol}$ ), $\mathrm{Pd}(\mathrm{OAc})_{2}(10 \mathrm{mg}, 0.04 \mathrm{mmol})$, and sodium tert-butoxide (210 $\mathrm{mg}, 2.18 \mathrm{mmol})$ were dissolved in toluene $(10 \mathrm{~mL})$ and then tri-tert-butyl phosphine $(1.6 \mathrm{~mL}, 0.05 \mathrm{M}$ in toluene, $0.08 \mathrm{mmol}$ ) was added. The mixture was heated under reflux under argon for $24 \mathrm{~h}$ and then quenched with water. The solvent was evaporated and then the reaction mixture was extracted with dichloromethane and dried $\left(\mathrm{MgSO}_{4}\right)$. The crude product was purified through column chromatography $\left(\mathrm{SiO}_{2}\right.$; EtOAc/hexane, $\left.1: 15\right)$ to afford TFVE1 (485 mg, 72\%) as a white solid. IR (KBr) v 3046 (w), 1600 (w), 1497 (s), $1460(\mathrm{w}), 1397$ (m), $1311(\mathrm{~m}), 1274(\mathrm{~s})$, $1192(\mathrm{~m}), 1159(\mathrm{~m}), 1136(\mathrm{~m}) \mathrm{cm}^{-1} .{ }^{1} \mathrm{H}$ NMR (acetone- $d_{6}$, $400 \mathrm{MHz}): \delta 7.98$ (d, $J=8.0 \mathrm{~Hz}, 2 \mathrm{H}), 7.94(\mathrm{~d}, J=8.0 \mathrm{~Hz}$, $2 \mathrm{H}$ ), 7.89 (d, $J=8.0 \mathrm{~Hz}, 2 \mathrm{H}), 7.55(\mathrm{t}, J=8.0 \mathrm{~Hz}, 2 \mathrm{H}), 7.52-$ $7.45(\mathrm{~m}, 6 \mathrm{H}), 7.43-7.36(\mathrm{~m}, 4 \mathrm{H}), 7.14-7.07(\mathrm{~m}, 8 \mathrm{H}), 7.00$ $(\mathrm{d}, J=8.0 \mathrm{~Hz}, 4 \mathrm{H}) .{ }^{13} \mathrm{C}$ NMR (acetone- $\left.d_{6}, 100 \mathrm{MHz}\right): \delta$ $148.0,146.3,143.8,136.2,134.5,131.8,129.3,127.9$, $127.8,127.6,127.3,127.2,127.0,124.5,124.2,122.3$, 117.6. ${ }^{19} \mathrm{~F}$ NMR (acetone- $d_{6}, 376 \mathrm{MHz}$ ): $\delta-117.1$ (dd, $J=99.6,55.6 \mathrm{~Hz}, 2 \mathrm{~F}),-124.3$ (dd, $J=108.3,99.3 \mathrm{~Hz}, 2 \mathrm{~F}$ ), 130.6 (dd, $J=108.3,56.4 \mathrm{~Hz}, 2 \mathrm{~F})$. MS $\left(\mathrm{FAB}^{+}, m / z\right) 780$ (100), 467 (25), 217 (35). HRMS (FAB ${ }^{+}, \mathrm{M}^{+}$) Calcd. $\mathrm{C}_{47} \mathrm{H}_{28} \mathrm{~N}_{4} 780.2211$, found 780.2208 .

TFVE2: A flask containing $3(2.46 \mathrm{~g}, 4.88 \mathrm{mmol}), 1-$ aminonaphthalene $(2.09 \mathrm{~g}, \quad 14.6 \mathrm{mmol}), \quad \mathrm{Pd}_{2}(\mathrm{dba})_{3}$ (224 mg, $0.25 \mathrm{mmol}$ ), and sodium tert-butoxide (1.41 g, $14.7 \mathrm{mmol}$ ) was evacuated and recharged with argon, then dry toluene $(30 \mathrm{~mL})$ and tri-tert-butylphosphine $(9.8 \mathrm{~mL}$, 
$0.05 \mathrm{M}$ in toluene, $0.49 \mathrm{mmol}$ ) were added. The mixture was heated under reflux for $48 \mathrm{~h}$ and then cooled to room temperature. The mixture was filtered through a short path of Celite and then washed with dichloromethane, and the filtrate was extract with dichloromethane and dried $\left(\mathrm{MgSO}_{4}\right)$. The solvent was partially removed using a rotary evaporator and then hexane $(30 \mathrm{~mL})$ was added to give a yellow solid that was collected through filtration and washed with hexane. The crude solid (1.9 g, $3.02 \mathrm{mmol}$ ) was combined with $\mathrm{Pd}(\mathrm{OAc})_{2}$ (34 mg, $0.15 \mathrm{mmol}), 2(1.91 \mathrm{~g}, 7.5 \mathrm{mmol})$, and sodium tert-butoxide $(1.44 \mathrm{~g}, 15 \mathrm{mmol})$ and then dry toluene $(40 \mathrm{~mL})$ and tritert-butylphosphine $(6 \mathrm{~mL}, 0.05 \mathrm{M}$ in toluene, $0.3 \mathrm{mmol}$ ) were added. The mixture was filtered through a short path of Celite and washed with ethyl acetate, and the filtrate was extracted with ethyl acetate and dried $\left(\mathrm{MgSO}_{4}\right)$. The solvent was removed using a rotary evaporator to give a crude product, which was purified through column chromatography ( $\mathrm{SiO}_{2}$; EtOAc:hexane, $\left.1: 20\right)$ to afford TFVE2 ( $2.3 \mathrm{~g}, 49 \%$ over two steps) as a yellow solid. IR (KBr) $v$ 3048 (m), 2917 (w), 2869 (w), 1831 (w), 1604 (m), 1573 (w), 1499 (s), 1465 (s), 1440 (m), 1392 (m), 1311 (s), 1274 (s), 1192 (s), $1164(\mathrm{~m}), 1137$ (s), $1019(\mathrm{w}), 816(\mathrm{~m})$, $798(\mathrm{~m}), 772(\mathrm{~m}) \mathrm{cm}^{-1} .{ }^{1} \mathrm{H}$ NMR $\left(\mathrm{CDCl}_{3}, 400 \mathrm{MHz}\right): \delta 7.94$ (d, J=4.2 Hz, 2H), $7.83(\mathrm{t}, J=8.8 \mathrm{~Hz}, 4 \mathrm{H}), 7.56$ (d, $J=4.6 \mathrm{~Hz}, 2 \mathrm{H}), 7.49(\mathrm{t}, J=8 \mathrm{~Hz}, 4 \mathrm{H}), 7.35(\mathrm{t}, J=6.8 \mathrm{~Hz}$, 2H), 7.28 (d, $J=3.4 \mathrm{~Hz}, 2 \mathrm{H}), 7.06$ (d, $J=4.6 \mathrm{~Hz}, 4 \mathrm{H}), 6.96$ $(\mathrm{m}, 8 \mathrm{H}), 6.85(\mathrm{~d}, J=4 \mathrm{~Hz}, 4 \mathrm{H}), 6.74(\mathrm{~d}, J=4.2 \mathrm{~Hz}, 4 \mathrm{H}), 2.21$ $(\mathrm{s}, 6 \mathrm{H}) .{ }^{13} \mathrm{C} \mathrm{NMR}\left(\mathrm{CDCl}_{3}, 100 \mathrm{MHz}\right): \delta 152.5,149.6,147.4$, 145.7, 143.3, 142.6, 135.8, 135.5, 134, 130.6, 128.6, 128.5, 127.7, 126.7, 126.6, 126.4, 126.2, 123.9, 123.4, 121, 120.4, 119.5, 116.8, 64.6, 20.2. ${ }^{19} \mathrm{~F}$ NMR (CDCl3, $\left.376 \mathrm{MHz}\right): \delta$ -115.8 (dd, $J=98.9,56.4 \mathrm{~Hz}, 2 \mathrm{~F}$ ), -123.0 (dd, $J=108.3$, $99.3 \mathrm{~Hz}, 2 \mathrm{~F}),-129.2$ (dd, $J=107.5,55.6 \mathrm{~Hz}, 2 \mathrm{~F})$. MS $\left(\mathrm{FAB}^{+}\right.$, $m / z) 973$ (100), 972 (35), 881 (15), 659 (30), 217 (20). HRMS $\left(\mathrm{FAB}^{+},[\mathrm{M}+\mathrm{H}]^{+}\right)$Calcd. $\mathrm{C}_{63} \mathrm{H}_{43} \mathrm{O}_{2} \mathrm{~N}_{2} \mathrm{~F}_{6}$ : 973.3230, found: 973.3238 .

TFVE3: 6 (2.1 g, $2 \mathrm{mmol}), 7(1.44 \mathrm{~g}, 4.8 \mathrm{mmol})$, and $\mathrm{Pd}\left(\mathrm{PPh}_{3}\right)_{4}(0.1 \mathrm{~g}, 0.086 \mathrm{mmol})$ were dissolved in 1,4-dioxane $(25 \mathrm{~mL})$ and then sodium carbonate $(10 \mathrm{~mL}, 2 \mathrm{M}$ in $\mathrm{H}_{2} \mathrm{O}$ ) was added. The mixture was heated under reflux under $\mathrm{Ar}$ for $72 \mathrm{~h}$ and then quenched with water, extracted with dichloromethane, and dried $\left(\mathrm{MgSO}_{4}\right)$. The crude product was purified through column chromatography $\left(\mathrm{SiO}_{2}\right.$; toluene/hexane, $1: 3)$ to afford TFVE3 $(1.2 \mathrm{~g}, 55 \%)$ as a yellow solid. IR (KBr) v 3056 (w), 2942 (w), 1592 (m), 1574 (m), 1492 (s), 1465 (m), 1429 (m), 1387 (w), 1310 (m), 1273 (s), $1197(\mathrm{~m}), 1175(\mathrm{~m}), 1138(\mathrm{~m}) \mathrm{cm}^{-1} \cdot{ }^{1} \mathrm{H}$ NMR (DMSO-d $\left.{ }_{6}, 400 \mathrm{MHz}\right): \delta 7.96(\mathrm{~d}, J=7.6 \mathrm{~Hz}, 2 \mathrm{H}), 7.84(\mathrm{~d}$, $J=8.0 \mathrm{~Hz}, 2 \mathrm{H}), 7.76(\mathrm{~d}, J=8.4 \mathrm{~Hz}, 2 \mathrm{H}), 7.64(\mathrm{t}, J=8.0 \mathrm{~Hz}$, $6 \mathrm{H}), 7.53-7.46(\mathrm{~m}, 4 \mathrm{H}), 7.40-7.36(\mathrm{~m}, 10 \mathrm{H}), 7.30(\mathrm{~d}$, $J=6.8 \mathrm{~Hz}, 2 \mathrm{H}), 7.18(\mathrm{t}, J=8.0 \mathrm{~Hz}, 4 \mathrm{H}), 6.93-6.84(\mathrm{~m}, 14 \mathrm{H})$. ${ }^{13} \mathrm{C}$ NMR (DMSO- $\left.d_{6}, 100 \mathrm{MHz}\right): \delta 153.4,150.8,147.3$, $146.7,143.9,142.4,137.0,136.4,134.7,133.0,129.9$, $129.0,128.7,128.4,128.2,127.7,126.5,126.4,126.2$, $126.0,123.3,121.8,121.4,120.6,120.5,118.4,115.9$, 63.8. ${ }^{19} \mathrm{~F}$ NMR (DMSO- $d_{6}, 376 \mathrm{MHz}$ ): $\delta-117.8$ (dd, $J=96.3,54.9 \mathrm{~Hz}, 2 \mathrm{~F}),-125.6(\mathrm{dd}, J=107.5,96.6 \mathrm{~Hz}, 2 \mathrm{~F})$, -133.6 (dd, $J=107.5,55.6 \mathrm{~Hz}, 2 \mathrm{~F})$. MS $\left(\mathrm{FAB}^{+}, \mathrm{m} / z\right) 1097$ (100), 880 (15), 217 (35). HRMS ([M+H] $\left.]^{+}, \mathrm{FAB}^{+}\right)$Calcd. $\mathrm{C}_{73} \mathrm{H}_{47} \mathrm{~F}_{6} \mathrm{~N}_{2} \mathrm{O}_{2}$ 1097.3543, found 1097.3534.

\subsection{Time-of-flight (TOF) mobility measurements}

In the TOF method, a sheet of carriers is created near one of the contacts using a short laser pulse (nitrogen pulse laser). The sample is illuminated from the indium tin oxide (ITO) side to generate a sheet of charge carriers in the organic layer. Under the influence of an applied electric field, these carriers drift toward the counter electrode $(\mathrm{Ag})$, resulting in a transient current through the sample. When the carriers reach the counter electrode, the current drops to zero; the point at which this happens corresponds to the transit time of the carriers $\left(t_{\mathrm{T}}\right)$. Depending on the polarity of the applied bias, selected photogenerated carriers (holes or electrons) are swept across the sample thickness $D$; the applied electric field $E$ is then equal to $V / D$, and the carrier mobility $(\mu)$ is given by $D /\left(t_{\mathrm{T}} E\right)$.

\subsection{OLED device}

The OLEDs were fabricated on ITO sheets having a resistance of $15 \Omega / \square$. The substrates were washed sequentially with isopropyl alcohol, acetone, and methanol in an ultrasonic bath, followed by UV-ozone treatment prior to use. A hole injecting poly(ethylene dioxythiophene): polystyrene sulfonate (PEDOT:PSS) layer was spin-coated onto the substrates and dried at $130{ }^{\circ} \mathrm{C}$ for $30 \mathrm{~min}$ to remove residual water. The substrates were transferred to a $\mathrm{N}_{2}$-filled glove box. The crosslinkable TFVE1-3 monomers (1.2 wt\%) were dissolved in THF, dip-coated atop the PEDOT:PSS layer to yield ca. 50-nm-thick films, and then cured at $230{ }^{\circ} \mathrm{C}$ for 30 min to promote crosslinking. To prepare the emissive and electron transport layer, a 60-nm layer of Alq3 was vacuum-deposited on top of the spin-coated HTL. The devices were then completed through thermal evaporation of the back electrode [ $\mathrm{LiF}(0.5 \mathrm{~nm}) / \mathrm{Ag}(100 \mathrm{~nm})]$ through a shadow mask. All evaporations were performed under a vacuum of less than $10^{-6}$ torr. Each device pixel had an active area of $0.25 \pi \mathrm{mm}^{2}$. The current-voltage-brightness $(I-V-L)$ characteristics of the devices were measured simultaneously using a Keithley 6430 source meter and a Keithley 6487 picoammeter equipped with a calibration Si-photodiode. EL spectra were measured using an ocean optics spectrometer.

\section{Results and discussion}

\subsection{Materials}

Scheme 1 depicts the syntheses of monomers TFVE1-3, which were derivatives of the well-established hole-transporting material $N, N^{\prime}$-di(1-naphthyl)- $N, N^{\prime}$-diphenylbenzidine ( $\alpha$-NPD). TFVE1, possessing two trifluorovinyl ether (TFVE) groups linked to the terminal phenylene rings of $\alpha$-NPD, was synthesized in an isolated yield of $72 \%$ through Pd-catalyzed amination of diamine $\mathbf{1}$ and compound 2 [20]. TFVE2, which had similar structural features to the terminal groups of TFVE1, but with the diarylamino groups attached to a coplanar rigid core (fluorene) to modulate the electronic properties, was synthesized through the reaction of 2,7-dibromo-9,9-ditolylfluorene (3) [29] with 

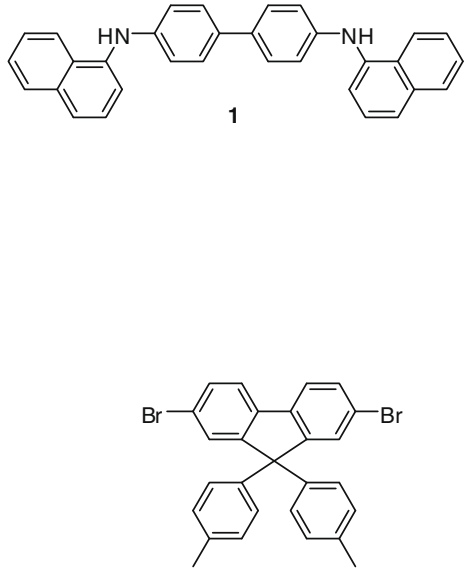

3
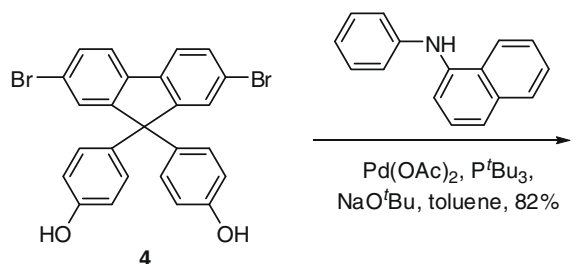

$\mathrm{Pd}(\mathrm{OAc})_{2}, \mathrm{P}^{t} \mathrm{Bu}_{3}$, $\mathrm{NaO}{ }^{t} \mathrm{Bu}$, toluene, $82 \%$

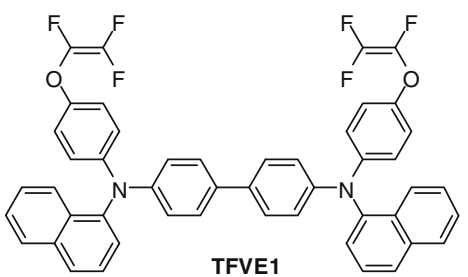

(1) 1-aminonaphthalene, $\mathrm{Pd}_{2}(\mathrm{dba})_{3}, \mathrm{P}^{t} \mathrm{Bu}_{3}$ $\mathrm{NaO}{ }^{t} \mathrm{Bu}$, toluene

(2) 2, $\mathrm{Pd}(\mathrm{OAc})_{2}, \mathrm{P}^{t} \mathrm{Bu}_{3}$, $\mathrm{NaO}{ }^{t} \mathrm{Bu}$, toluene 2 steps, $49 \%$<smiles>Cc1ccc(C2(c3ccc(C)cc3)c3cc(N(c4ccc(OC(F)=C(F)F)cc4)c4cccc5ccccc45)ccc3-c3ccc(N(c4ccc(OC(F)=C(F)F)cc4)c4cccc5ccccc45)cc32)cc1</smiles>

TFVE2
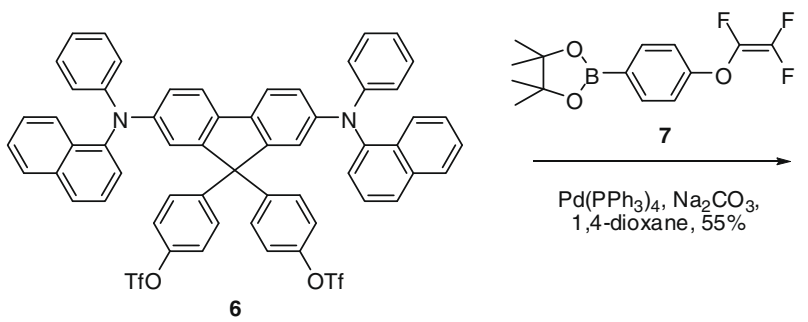

$\mathrm{Pd}\left(\mathrm{PPh}_{3}\right)_{4}, \mathrm{Na}_{2} \mathrm{CO}_{3}$, 1,4-dioxane, $55 \%$<smiles>Oc1ccc(C2(c3ccc(O)cc3)c3cc(N(c4ccccc4)c4cccc5ccccc45)ccc3-c3ccc(N(c4ccccc4)c4cccc5ccccc45)cc32)cc1</smiles>

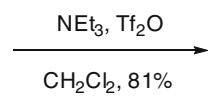

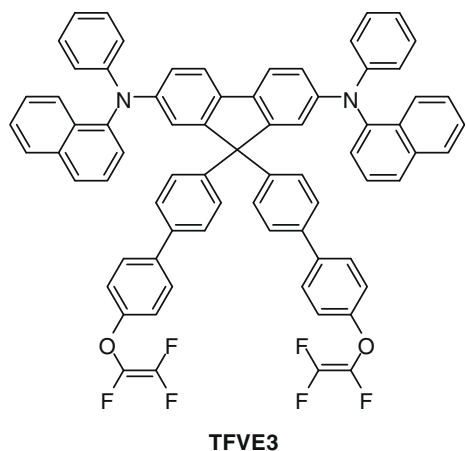

Scheme 1. Synthesis of trifluorovinyl ether-functionalized monomers TFVE1-3.

1-aminonaphthalene in the presence of a catalytic amount of $\mathrm{Pd}_{2}(\mathrm{dba})_{3}$ to furnish an aminated crude product that was subsequently subjected to Pd-catalyzed amination with compound 2 (49\% yield over two steps). Without structural perturbation of the active chromophore, the two TFVE groups of TFVE3 were introduced onto the peripheral biphenyl substituents of the central fluorene unit. The amination of compound 4 [30] with $N$-phenyl-1-naphthylamine in the presence of a catalytic amount of $\mathrm{Pd}(\mathrm{OAc})_{2}$ and tri-tertbutyl phosphine gave compound $\mathbf{5}$ in $82 \%$ yield. The treatment of the phenol groups in $\mathbf{5}$ with trifluoromethane- sulfonic anhydride afforded the disulfonate 6 in $81 \%$ yield. TFVE3 was then obtained in 55\% yield after Suzuki coupling of the boronic ester 7 [15] and compound 6 .

\subsection{Physical properties}

The morphological properties of the monomers TFVE13 were investigated using differential scanning calorimetry (DSC). The introduction of two TFVE groups had a pronounced effect on the morphology. As indicated in Fig. 1, no evident glass transition could be detected for TFVE1; in- 


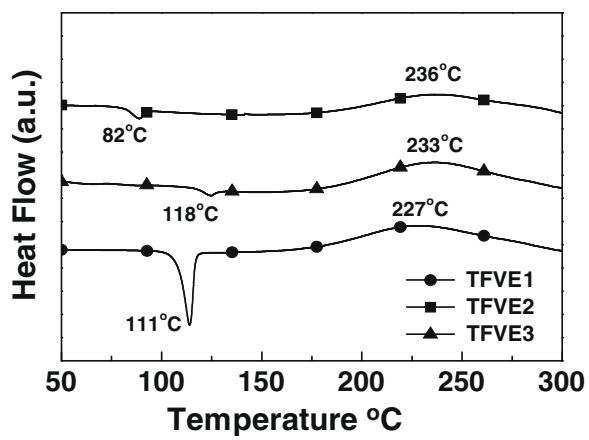

Fig. 1. DSC analyses of the thermally polymerizable monomers TFVE1-3.

stead, we observed an endothermic peak centered at $111^{\circ} \mathrm{C}$, which corresponded to the melting point of TFVE1. The increased molecular rigidity of TFVE2 led to a distinct glass transition temperature $\left(T_{\mathrm{g}}\right)$ detected at $82^{\circ} \mathrm{C}$, which remained significantly lower than that of its parent compound $\left(127^{\circ} \mathrm{C}\right)$ [29]. TFVE3, with its two TFVE groups attached to the peripheral biphenyl substituents of the central fluorene unit, possesses a value of $T_{\mathrm{g}}$ of $118^{\circ} \mathrm{C}$. The exothermic peaks of TFVE1-3 at ca. $230^{\circ} \mathrm{C}$ in the DSC traces correspond to their thermal polymerizations, consistent with the previously reported polymerization temperatures of TFVE groups [14-28]. The three TFVE monomers were soluble in common organic solvents, such as chloroform, tetrahydrofuran (THF), and toluene. After dip-coating solutions of the TFVEs in THF onto ITO substrates, the films were baked at $100{ }^{\circ} \mathrm{C}$ for $30 \mathrm{~min}$ to remove any residual solvent. Atomic force microscopy (AFM) reveals that the films prepared through this dipcoating process had smooth surfaces with no obvious crystallization, pinholes, or cracks (Fig. 2). After curing at $230{ }^{\circ} \mathrm{C}$ for $60 \mathrm{~min}$, the films of the PFCB polymers became insoluble in most organic solvents. The AFM images of these PFCB polymer films reveal some clusters formed after thermal polymerization at high temperature.

Fig. 3a displays UV-vis absorption and photoluminescence spectra of the thin films of vacuum-deposited $\alpha$-NPD and TFVE1-3 after thermal polymerization. The absorption spectrum $\left(\lambda_{\max }=344 \mathrm{~nm}\right)$ of TFVE1 polymer matches well with that of $\alpha$-NPD, whereas polymers of TFVE2 and TFVE3 exhibit red-shifted absorption maxima (by ca. $40 \mathrm{~nm}$ ), due to the coplanar structure of their cores. There were no significant changes in the absorption spectra of TFVE1-3 after the treatment at high temperature (Fig. $3 \mathrm{~b}$ and $\mathrm{c}$ ). In contrast to their electronic transitions, the emission spectra of the thermally polymerized thin films of TFVE1-3 exhibit slightly red-shifted maxima with broader half-widths of the emission peaks, relative to that of the $\alpha$-NPD thin film and the thin films of TFVE1-3 prior to thermal polymerization. These results contrast those from a previous report by Jen et al., where a thin film of a $N, N^{\prime}$-di(3-methylphenyl)- $N, N^{\prime}$-diphenylbenzidine (TPD)based PFCB polymer exhibited an obviously red-shifted emission maximum relative to that of its monomer film as a result of strong aggregation and excimer emission [22-28]. The observed limited red shifts in the emission of TFVE1-3 polymers and their long-wavelength tails could be attributable to the changes in the dielectric environments upon thermal treatment. The chromophores surrounded by TFVE moieties in the monomeric states should behave differently from those in the polymeric forms, in which the TFVE groups have been converted into PFCB moieties. Nevertheless, we cannot exclude the possibility of weak interchromophore interactions leading to longwavelength emission regions in the polymer films after high-temperature thermal polymerization.

To characterize the hole transport in these thermally polymerized TFVE1-3 polymers and to quantify their mobilities, we used time-of-flight (TOF) techniques [31]

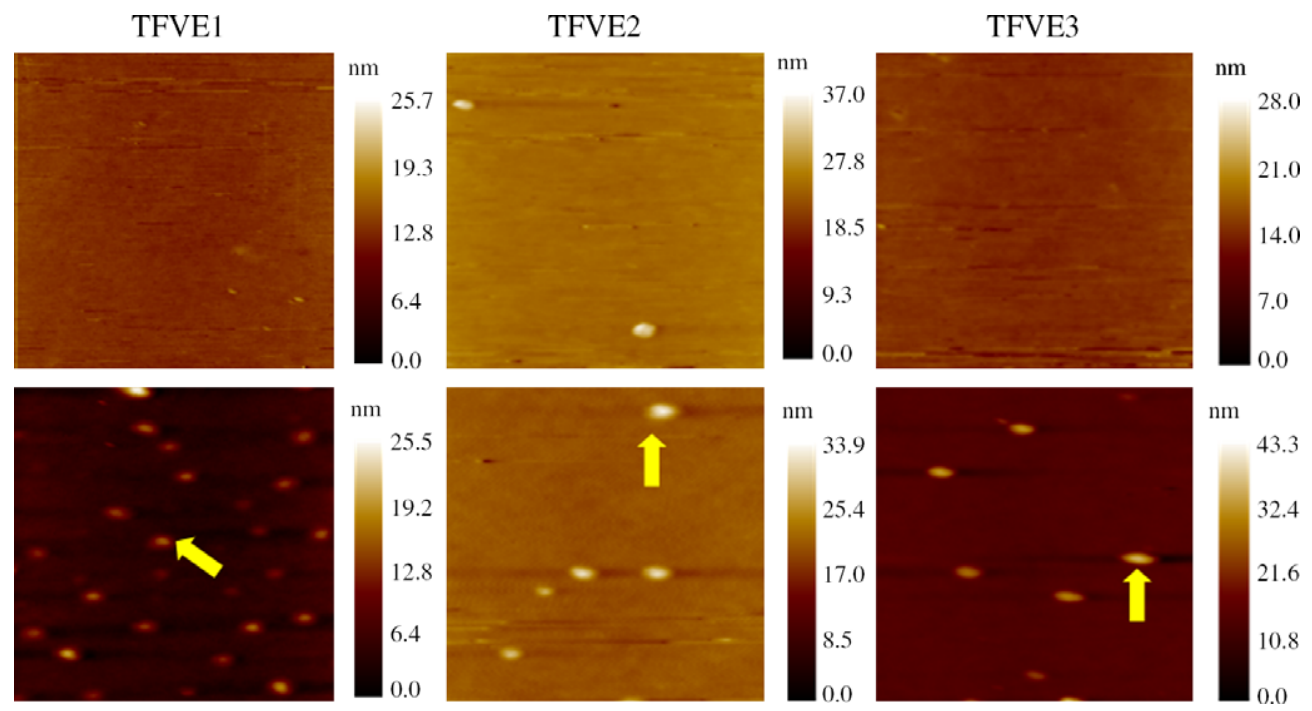

Fig. 2. AFM images $(5 \times 5 \mu \mathrm{m})$ of TFVE1-3 thin films before (top) and after (bottom) thermal polymerization. The indicated clusters with heights of TFVE1 $(11 \mathrm{~nm})$, TFVE2 $(13 \mathrm{~nm})$, and TFVE3 $(16 \mathrm{~nm})$, respectively. 

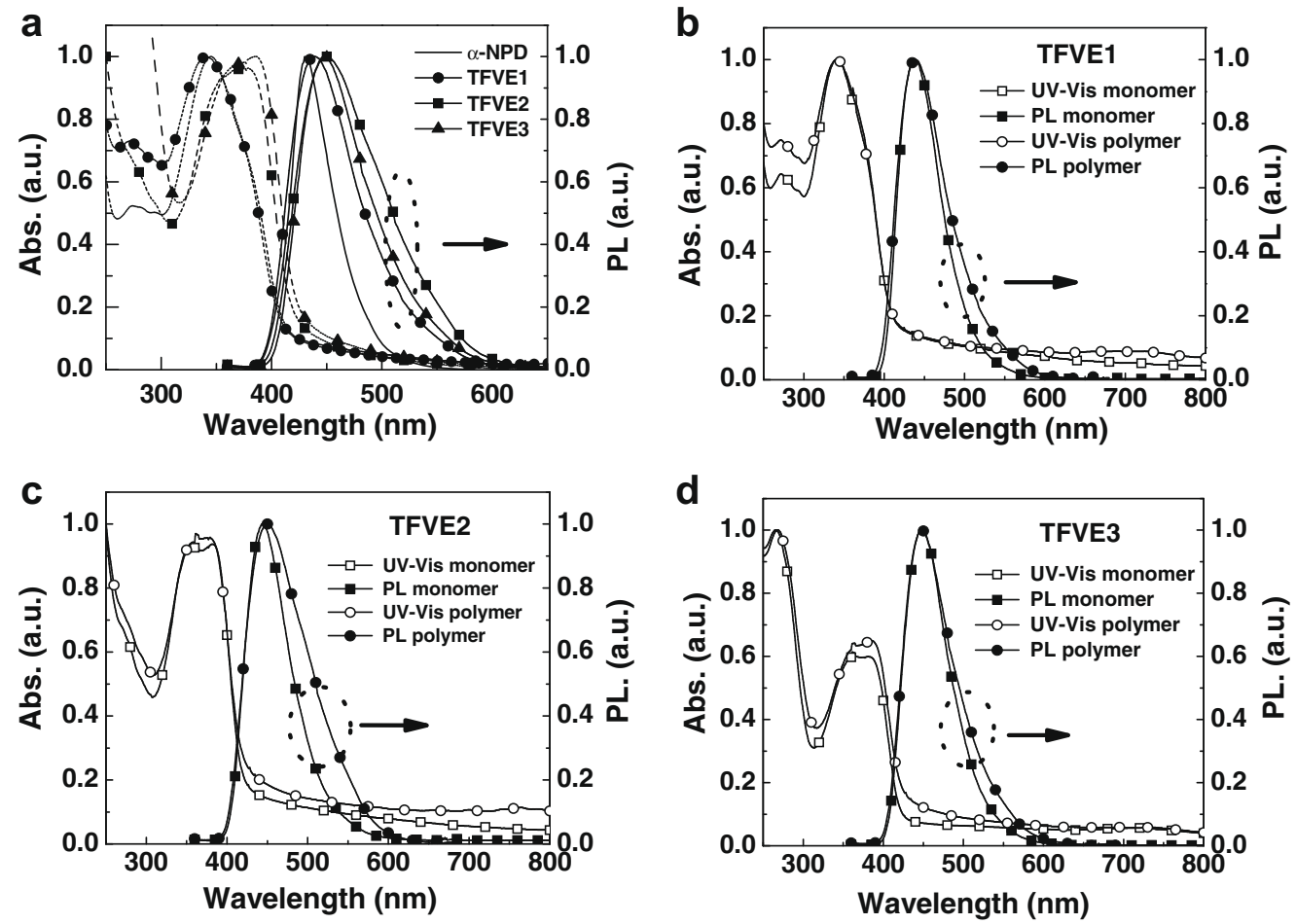

Fig. 3. (a) UV-vis absorption and photoluminescence spectra of thin films of thermally polymerized TFVE1-3 and vacuum-deposited $\alpha$-NPD and (b-d) comparisons of photophysical properties of TFVE1-3 thin films before (monomers) and after thermal polymerization (polymers).

to measure the charge carrier mobility. This technique has been successfully applied to investigate the charge transport behavior of a wide range of polymers and small molecules, but it has not been applied previously to measure the charge mobility of any thermal polymerized and/or cross-linked polymers. TOF samples were prepared by dissolving appropriate weight ratios (up to $25 \mathrm{wt} \%$ ) of the monomers TFVE1 and TFVE2 in THF and then dip-coating the solutions onto an ITO substrate within a glove box. For TFVE3, however, poor solubility in THF meant that we could not obtain a solution of sufficiently high concentration to yield a sample that was thick enough for TOF measurement. We were able to control the film thicknesses by varying the solution concentrations and the dip-coating conditions; the films were subsequently dried through baking at $100{ }^{\circ} \mathrm{C}$ for $30 \mathrm{~min}$ to remove the residual solvent and then curing at $230^{\circ} \mathrm{C}$ for $60 \mathrm{~min}$ to form the polymers. We used a Dektak surface profilometer to measure the thicknesses of the TFVE1 (ca. $760 \mathrm{~nm}$ ) and TFVE2 (ca. $500 \mathrm{~nm}$ ) polymer films. The samples were then completed through thermal deposition of the back electrode [Ag $(100 \mathrm{~nm})]$ through a shadow mask.

Fig. 4 displays the TOF transients of the TFVE1 and TFVE2 polymer films. Distinctive plateaus are visible in the typical TOF transient photocurrents, indicating the non-dispersive transport behavior of the TFVE1 and TFVE2 polymers toward holes. We estimated the carrier transit times $t_{\mathrm{T}}$ from the asymptotes of the log-log plots (insets to Fig. 4); from these values, we deduced the hole mobilities $(\mu)$ using the relation $\mu=d /\left(E t_{\mathrm{T}}\right)$, where $E$ and $d$ are the applied electric field and the thickness of the organic film,
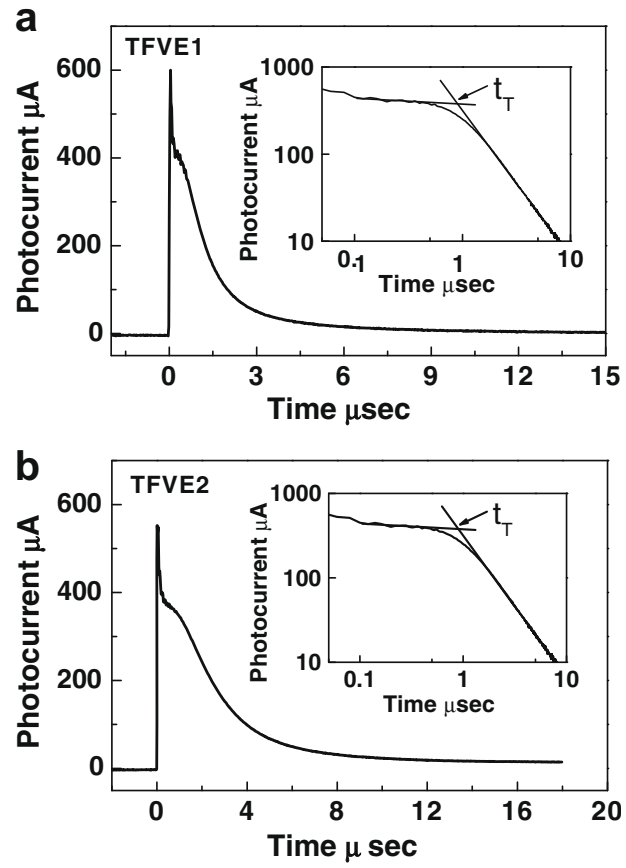

Fig. 4. Representative TOF transients for polymer films derived from (a) TFVE1 (at $E=5.3 \times 10^{5} \mathrm{~cm} \mathrm{~V}^{-1}$ ) and (b) TFVE2 (at $E=6.1 \times 10^{5} \mathrm{~cm} \mathrm{~V}^{-1}$ ) at room temperature. The insets present double-logarithmic plots of the data.

respectively. Fig. 5 presents the room-temperature hole mobilities of the model compound $\alpha$-NPD and of the 


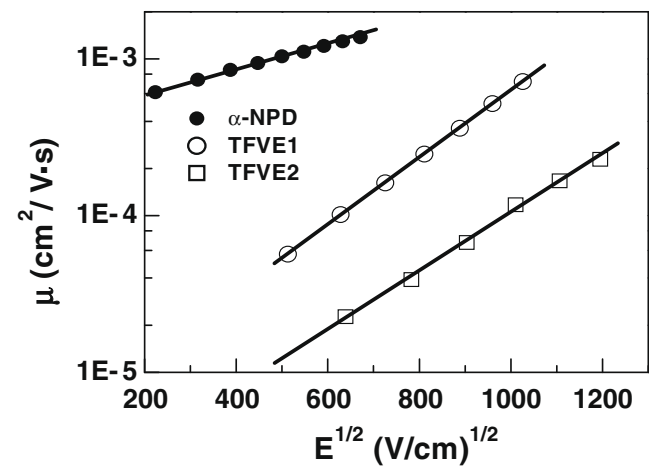

Fig. 5. Plots of hole mobilities vs. $E^{1 / 2}$ for the thermally polymerized films of TFVE1 and TFVE2 2 and of a film of the model compound $\alpha$-NPD obtained through thermal evaporation.

PFCB-based polymer films derived from TFVE1 and TFVE2 plotted against the square root of the applied electric field. The linear correlation follows the universal Poole-Frenkel relationship, $\mu=\mu_{0} \exp \left(\beta E^{12}\right)$, where $\mu_{0}$ is the zero-field mobility, $\beta$ is the Poole-Frenkel factor and $E$ is the electric field [32]. The hole mobilities ranged from $2 \times 10^{-5}$ to $10^{-3}$ $\mathrm{cm}^{2} \mathrm{~V}^{-1} \mathrm{~s}^{-1}$ for fields varying from $4 \times 10^{4}$ to $1.4 \times$ $10^{6} \mathrm{~V} \mathrm{~cm}^{-1}$ and the values $\left(\mu_{0}\right.$ and $\beta$ ) of fitting data are summarized in Table 1.

The observed hole mobility $\left(\mu_{\mathrm{h}}=\mathrm{ca} \cdot 10^{-4} \mathrm{~cm}^{2} \mathrm{~V}^{-1} \mathrm{~s}^{-1}\right)$ of the TFVE1-derived polymer film was about one order of magnitude lower than that of the model compound $\alpha$-NPD $\left(\mu_{\mathrm{h}}=1.2 \times 10^{-3} \mathrm{~cm}^{2} \mathrm{~V}^{-1} \mathrm{~s}^{-1}\right)$ under the same electric field $\left(E=3.6 \times 10^{5} \mathrm{~V} \mathrm{~cm}^{-1}\right)$. In addition, as indicated by it larger value of $\beta$, the TFVE1-derived polymer film exhibited a stronger electric-field-dependent hole mobility. We ascribe these phenomena to the presence of the PFCB units of the TFVE1-derived polymer; i.e., the more rigid structure and the larger distance and steric hindrance between neighboring chromophores increased the carrier hopping distance, thus retarding hole migration. The aggregates observed in the AFM images of the thermally treated thin films might also have been another attribute responsible for the lower hole mobility. The steric effect on hole transportation was also evident from the lower hole mobility of

Table 1

The values of zero-field hole mobility $\left(\mu_{0}\right)$ and Poole-Frenkel factor $(\beta)$ obtained by fitting the data in Fig. 5 with the Poole-Frenkel equation.

\begin{tabular}{lll}
\hline HTL & {$\left[\mathrm{cm}^{2} \mathrm{~V}^{-1} \mathrm{~s}^{-1}\right]$} & $\beta$ \\
\hline $\boldsymbol{\alpha}$-NPD & $4.18 \times 10^{-4}$ & $1.79 \times 10^{-3}$ \\
TFVE1 & $4.53 \times 10^{-6}$ & $4.93 \times 10^{-3}$ \\
TFVE2 & $1.46 \times 10^{-6}$ & $4.27 \times 10^{-3}$ \\
\hline
\end{tabular}

the TFVE2-derived polymer (a 9,9-ditolylfluorene-based diamine) relative to that of the TFVE1-derived polymer (a biphenylene-based diamine) [33].

\subsection{Device}

To evaluate the performances of devices incorporating the thermally polymerized TFVE1-3 films as HTLs, we fabricated two-layer devices having the configuration ITO/ PEDOT:PSS (30 nm)/polymeric TFVE1-3 (ca. $50 \mathrm{~nm}$ )/Alq $(60 \mathrm{~nm}) / \mathrm{LiF}(0.5 \mathrm{~nm}) / \mathrm{Al}(100 \mathrm{~nm})$. Uniform films were formed through first dip-coating the solution of TFVE1-3 (1.2 wt\% in THF) onto the pre-dried $\left(130{ }^{\circ} \mathrm{C}\right.$ for $\left.30 \mathrm{~min}\right)$ PEDOT:PSS layer on an ITO substrate [34,35] and then polymerizing under thermal treatment at $230^{\circ} \mathrm{C}$ for $30 \mathrm{~min}$. Integrating the conductive HIL and the thermally polymerized HTL together resulted in a low driving
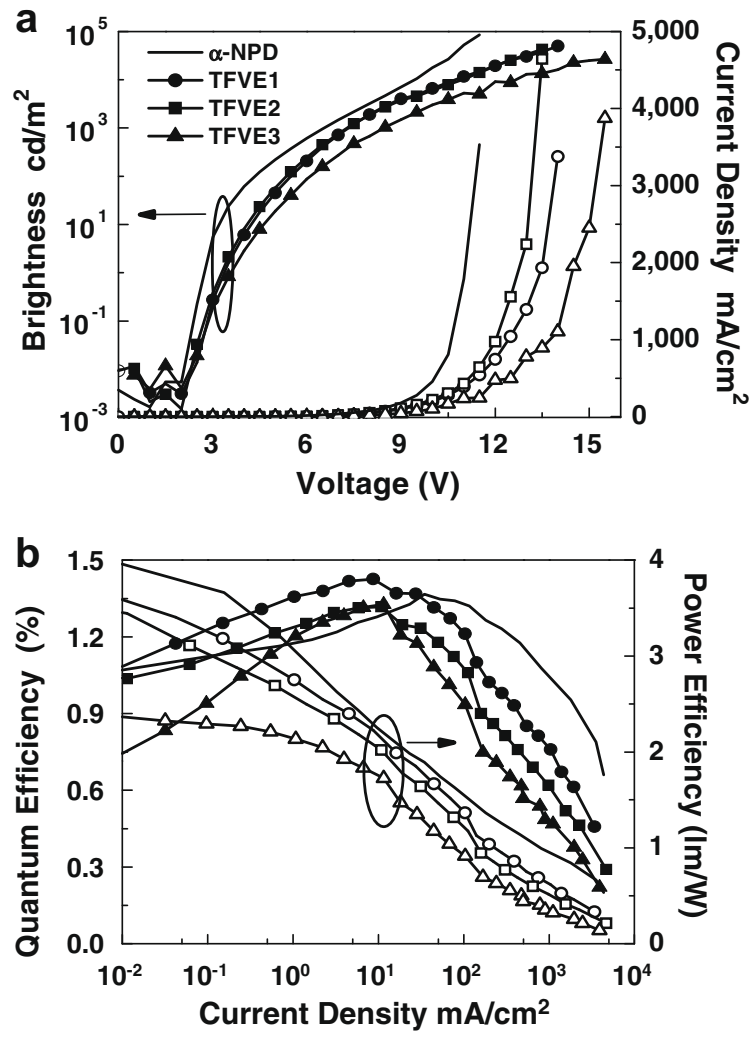

Fig. 6. Performances of typical two-layer devices incorporating thermally polymerized HTLs and $\alpha$-NPD. Plots of (a) brightness (solid symbols) and current (open symbols) vs. voltage and (b) quantum efficiency (solid symbols) and power efficiency (open symbols) vs. current.

Table 2

Device characteristics of OLEDs incorporating cross-linked TFVE1-3 and vacuum-deposited $\boldsymbol{\alpha}$-NPD as HTLs.

\begin{tabular}{lllll}
\hline HTL & $V_{\text {on }}[\mathrm{V}]$ & $L_{\max }\left[\mathrm{cd} \mathrm{m}^{-2}\right]$ & $I_{\max }\left[\mathrm{mA} \mathrm{cm}^{-2}\right]$ & $\eta_{\text {ext }}\left(\mathrm{max}\left[\%, \mathrm{~cd} \mathrm{~A}{ }^{-1}\right]\right.$ \\
\hline $\boldsymbol{\alpha}$-NPD & 2 & $86,000(11.5 \mathrm{~V})$ & 3500 & $1.36,4.4$ \\
TFVE1 & 2 & $50,000(14.0 \mathrm{~V})$ & 3400 & $1.43,4.6$ \\
TFVE2 & 2 & $43,000(13.5 \mathrm{~V})$ & 4600 & 3.6 \\
TFVE3 & 2 & $26,600(14.0 \mathrm{~V})$ & 3900 & 3.3 \\
\end{tabular}


voltage, cascade hole injection, and effective electron blocking/exciton confinement in the $\mathrm{Alq}_{3}$ layer. All devices exhibited the same emission, which originated exclusively from the $\mathrm{Alq}_{3}$ layer.

Table 2 and Fig. 6 summarize the EL characteristics of the OLEDs incorporating the thermally polymerized TFVE1-3 monomers and vacuum-deposited $\alpha$-NPD as HTLs. These hybrid OLEDs exhibit noteworthy properties relative to those of conventional vacuum-deposited OLEDs. For example, the thermally polymerized HTLs functioned well without decreasing the device performance [10]. As indicated in Fig. 5a, the devices turned on sharply at low voltages (ca. $2 \mathrm{~V}$ ), probably because the HOMO and LUMO energy levels of the active triaryldiamine chromophores, which remained intact before and after thermal polymerization, were matched well with those of ITO and $\mathrm{Alq}_{3}$. Among our three new thermally polymerizable HTL materials, the TFVE1-derived polymer exhibited the best performance. Fig. 5b indicates that the highest efficiency was achieved when using the TFVE1-derived polymer as the HTL: the maximum EQE was $1.43 \%\left(4.6 \mathrm{~cd} \mathrm{~A}^{-1}\right)$ and the maximum power efficiency was $3.6 \mathrm{~lm} \mathrm{~W}^{-1}$. It is generally accepted that polymers exhibiting high morphological stability in their thin film form result in devices that can endure relatively high current densities (ca. $3400 \mathrm{~mA} \mathrm{~cm}^{-2}$ ) and, consequently, emit an impressive maximum brightness of nearly $5 \times 10^{4} \mathrm{~cd} \mathrm{~m}^{-2}$ at ca. $14 \mathrm{~V}$ from the nondoped $\mathrm{Alq}_{3}$. Despite the lower hole mobility of the TFVE1-derived polymer films, compared with that of the vacuum-deposited model compound $\alpha$-NPD, the device incorporating the former as the HTL exhibited the same turn-on voltage and slightly higher EQE (1.43\%) relative to that of the latter $(\mathrm{EQE}=1.37 \%)$ under the same device structure. We attributed the higher EQE achieved in the hybrid OLED to a more balanced recombination of holes and electrons.

\section{Conclusions}

In summary, we have synthesized and characterized three thermally polymerizable hole-transporting materials, TFVE1-3, derived from the parent $\alpha$-NPD core through the attachment of TFVE groups. The thermally polymerized monomers exhibited good thermal properties, solvent resistance, and relatively high surface smoothness. More importantly, for the first time we used TOF techniques to measure the hole-transporting characteristics of $\alpha$-NPDbased PFCB polymers. We observed a hole mobility of ca. $10^{-4} \mathrm{~cm}^{2} \mathrm{~V}^{-1} \mathrm{~s}^{-1}$ for TFVE1-derived polymer films, ca. one order of magnitude lower than that of the model compound $\alpha$-NPD (i.e., in the absence of TFVE groups) under the same electric filed. We ascribe the lower mobilities of the PFCB-based polymers to their larger degrees of spatial and steric hindrance leading to blocking of carrier hopping. We fabricated hybrid OLEDs incorporating the TFVE1-derived polymer film as the HTL. These devices exhibited high current densities (ca. $3400 \mathrm{~mA} \mathrm{~cm}^{-2}$ ), impressive brightness $\left(5 \times 10^{4} \mathrm{~cd} \mathrm{~m}^{-2}\right)$, and high external quantum efficiency $(1.43 \%)$.

\section{Acknowledgement}

This study was supported financially by the National Science Council of Taiwan.

\section{References}

[1] C.W. Tang, S.A. VanSlyke, Appl. Phys. Lett. 51 (1987) 913.

[2] A.R. Brown, R.N. Marks, K. Mackay, R.H. Friend, P.L. Burns, A.B Holmes, Nature (London) 3471 (1990) 539.

[3] B. Yan, B.J. Scott, Q. Huang, Q. Marks, Adv. Mater. 16 (2004) 1948.

[4] C.D. Müller, A. Falcou, N. Reckefuss, M. Rojahn, V. Wiederhirn, P. Rudati, H. Frohne, O. Nuyken, H. Becker, K. Meerholz, Nature (London) 421 (2003) 829.

[5] M.C. Gather, A. Köhnen, A. Falcou, H. Becker, K. Meerholz, Adv. Funct. Mater. 17 (2007) 191

[6] R.J.P. Corriu, D. Leclercq, Angew. Chem., Int. Ed. Eng. 35 (1996) 1420.

[7] U. Schubert, N. Hüsing, A. Lorenz, Chem. Mater. 7 (1995) 2010

[8] W. Li, Q. Wang, J. Cui, H. Chou, S.E. Shaheen, G.E. Jabbour, J. Anderson, P. Lee, B. Kippelen, N. Peyghambarian, N.R. Armstrong, T.J. Marks, Adv. Mater. 11 (1999) 730.

[9] J.G.C. Veinot, T.J. Marks, Accounts Chem. Res. 38 (2005) 632.

[10] E. Bellmann, S.E. Shaheen, S. Thayumanavan, S. Barlow, R.H. Grubbs, S.R. Marder, B. Kippelen, N. Peyghambarian, Chem. Mater. 10 (1998) 1668.

[11] A. Kimyonok, B. Domercq, A. Haldi, J.-Y. Cho, J.R. Carlise, X.-Y. Wang, L.E. Hayden, S.C. Jones, S. Barlow, S.R. Marder, B. Kippelen, M. Weck, Chem. Mater. 19 (2007) 5602.

[12] A. Bacher, C.H. Erdelen, W. Paulus, H. Ringsdorf, H.-W. Schmidt, P. Schuhmacher, Macromolecules 32 (1999) 4551.

[13] Y.-H. Niu, M.S. Liu, J.-W. Ka, J. Bardeker, M.T. Zin, R. Schofield, Y. Chi, A.K.-Y. Jen, Adv. Mater. 19 (2007) 300.

[14] B.K. Spraul, S. Suresh, U.Y. Jin, D.W. Smith Jr., J. Am. Chem. Soc. 128 (2006) 7055.

[15] B. Lim, J.-T. Hwang, J.Y. Kim, J. Ghim, D. Vak, Y.-Y. Noh, S.-H. Lee, K. Lee, A.J. Heeger, D.-Y. Kim, Org. Lett. 8 (2006) 4703.

[16] B.K. Spraul, S. Suresh, S. Glaser, D. Perahia, J. Ballato, D.W. Smith Jr., J. Am. Chem. Soc. 126 (2004) 12772

[17] A.R. Neilson, S.M. Budy, J.M. Ballato, D.W. Smith Jr., Macromolecules 40 (2007) 9378.

[18] J. Ghim, H.-S. Shim, B.G. Shin, J.-H. Park, J.-T. Hwang, C. Chun, S.-H. Oh, J.-J. Kim, D.-Y. Kim, Macromolecules 38 (2005) 8278.

[19] J. Ji, S. Narayan-Sarathy, R.H. Neilson, J.D. Oxley, D.A. Babb, N.G. Rondan, D.W. Smith, Macromolecules 17 (1998) 783.

[20] D.W. Smith, D.A. Babb, Macromolecules 29 (1996) 852.

[21] D.A. Babb, B.R. Ezzell, K.S. Clement, W.F. Richey, A.P. Kennedy, J. Polym. Sci. Part A: Polym. Chem. 31 (1993) 3465.

[22] Y.-H. Niu, Y.-L. Tung, Y. Chi, C.-F. Shu, J.H. Kim, B. Chen, J. Luo, A.J. Carty, A.K.-Y. Jen, Chem. Mater. 17 (2005) 3532.

[23] X. Gong, D. Moses, A.J. Heeger, S. Liu, A.K.-Y. Jen, Appl. Phys. Lett. 83 (2003) 183.

[24] X. Jiang, S. Liu, M.S. Liu, P. Herguth, A.K.-Y. Jen, H. Fong, M. Sarikaya, Adv. Funct. Mater. 12 (2002) 745.

[25] S. Liu, X. Jiang, H. Ma, M.S. Liu, A.K.-Y. Jen, Macromolecules 33 (2000) 3514.

[26] X. Jiang, M.S. Liu, A.K.-Y. Jen, J. Appl. Phys. 91 (2002) 10147.

[27] Y.H. Niu, B. Chen, S. Liu, H. Yip, J. Bardecker, A.K.-Y. Jen, J. Kavitha, C.F. Shu, Y. Chi, Y.-H. Tseng, C.-H. Chien, Appl. Phys. Lett. 85 (2004) 1619.

[28] J. Zhao, J. Bardecker, A.M. Munro, M.S. Liu, Y. Niu, I.-K. Ding, J. Luo, B. Chen, A.K.-Y. Jen, D.S. Ginger, Nano Lett. 6 (2006) 463.

[29] K.-T. Wong, Z.-J. Wang, Y.-Y. Chien, C.-L. Wang, Org. Lett. 3 (2001) 2285.

[30] C.-H. Chou, C.-F. Shu, Macromolecules 35 (2002) 9673.

[31] P.M. Borsenberger, D.S. Weiss, Organic Photoreceptors for Imaging Systems, Marcel Dekker, New York, 1993.

[32] P.M. Borsenberger, L. Pautmeier, H. Bässler, J. Chem. Phys. 94 (1991) 5447.

[33] Y.-L. Liao, W.-Y. Hung, T.-H. Hou, C.-Y. Lin, K.-T. Wong, Chem. Mater. 19 (2007) 6350

[34] Y. Cao, G. Yu, C. Zhang, R. Menon, A.J. Heeger, Synth. Metal. 87 (1997) 171.

[35] A. Berntsen, Y. Croonen, C. Liedenbaum, H. Schoo, R.-J. Visser, J. Vleggaar, P. van de Weijer, Opt. Mater. 9 (1998) 125. 